one hand, and with carbon and hydrogen on the other, as in the explosives, e.g. nitroglycerine.

Living substance has apparently all the above mentioned sources of instability, and perhaps not the least important is that it has for its pivot nitrogen, the element which above all others is remarkable for the lability of its compounds. I have elsewhere ${ }^{2}$ indicated the probability that the active molecule of living substance consists of an enormous complex of proteids, carbohydrates, \&c., linked together by means of the nitrogen atoms, and that the oxygen store is more or less combined with the nitrogen. At the death of the molecule its constituent groups (proteids, \&c.) are released, and the store of oxygen passes from the nitrogen into other and more stable forms of combination.

Cambridge.

\section{Chalk Masses in the Cliffs near Cromer.}

At the present time the cliffs near Cromer exhibit some interesting chalk masses in the Glacial drifts. Between East and West Runton Gaps are several of great size and remarkable in position. One, a very long slab-like mass, is bent from being nearly horizontal until it is almost vertical, and thus comes to within a short distance of the top of the cliff. The masses near Trimingham will now repay a close study, for they have changed greatly during the last five years. Both my friend, the Rev. E. Hill, and I have made notes and rough sketches, with the intention of sending to the Geological Magazine a short account of what can now be seen; but we earnestly hope that some geologists who are adepts at photography will visit both localities at the earliest possible opportunity, in order to secure a permanent and accurate record of these exceptionally interesting sections.

T. G. BONNEY.

\section{The Rigidity of the Earth's Interior.}

The letter of Dr. T. J. J. See (Nature, April 13, p. 559) deals with a subject of profound interest to students of the larger problems connected with physical geology. But it appears that, in Dr. See's treatment of the subject, he has overlooked an important point, which I dealt with in a paper read before Section $\mathbf{C}$. of the British Association at Birmingham in 1886 . Therein I directed attention to the fact that "gravitation" is only a special instance of the law of universal attraction, and as a corollary to this, at any considerable depth within the sphere of the earth, an appreciable factor of what I may call negative gravity must be allowed for, owing to the counterattraction of the mass of matter situated nearer the surface of the sphere; so that a body placed at the centre of gravity of the earth, whatever its mass or density, would have no weight at all.

I am glad to see that the consideration of "critical temperatures" of quasi-solids (the importance of which was emphasised in my little. work on metamorphism some fifteen years ago) is receiving serious attention, and I may also point out that the idea of a potentially liquid (or even gaseous) condition of a mass at depths in a practically rigid state is not new; it was treated in a masterly way by Prof. Albert Heim, of Zürich, some twenty years ago, in his magnificent work "Ueber den Mechanismus der Gebirgsbildung." "Ueberlastet" is the word used by Heim to express such conditions, where the pressure is so far " hydrostatic" as to consist of compression acting equally (for the time being) in all directions. Any disturbance in a given portion of the lithosphere of the equilibrium thus existing must result in shearing movement if the disturbance be small, and in floze in a given direction if the relief in that direction from pressure is great and rapid enough. In the former case we should get "metataxic change," in the latter schistosity; for I still challenge the statement, made recently by a high authority, that "it is only a question of degree between the cleavage of a slate and the foliation of a crystalline schist or gneiss."

Questions relating to tidal action in the rotating lithosphere, and even Lord Kelvin's oft-repeated objection on

1 Report Brit. Assoc., 1896 , p. 983 ; and Proc. Birmingham Nat. Hist. and Philos. Soc., 1899.

NO. 1853 , vOL. 72$]$ that ground to the impossibility of any considerable portion of the lithosphere being fluid, because the earth does not undergo the deformation which the physicist would expect owing to the tidal action which should be set up within it, might possibly be seen in a fresh light on taking into account the remarkable facts demonstrated by Prof. John Perry in his lecture on spinning tops, which he gave to an audience of working men on the occasion of the meeting of the British Association at Leeds in 1890. As a "working man" in a real sense of the word, I considered myself privileged to attend that lecture, and was rewarded by finding in my own mind a great difficulty cleared up by Prof. Perry's masterly demonstrations of the practically rigid condition of non-rigid bodies, if only made to rotate with sufficient rapidity, as the equatorial regions of the earth do-something like rooo miles an hour.

$$
\text { Bishop's Stortford, April } 17 .
$$

A. IRving.

\section{Rival Parents.}

A curious example of the rival claims of a pair of thrushes and a pair of blackbirds for the parentage of a young blackbird is being observed in my garden.

A pair of blackbirds built a nest in a small thick laurel, and in another shrub, some 4 feet off, a pair of thrushes also built a nest. The young in both nests were hatched out at the same time, and were successfully reared until they were some eight or nine days oId, when a cat attacked the nests (Monday, April 17), killing all the young thrushes and all the blackbirds except one, which was found hidden under the shrubs. It was continually visited after the tragedy by both the old thrushes and old blackbirds, and two or three hours later was removed in some way not observed to a shrubbery twenty or thirty yards away. There for the last five days it has been fed and looked after by both pairs of birds, who mob with exceptional vigour any intruding cat or dog. The young bird seems to have thriven mightily under the attentions of its true and foster parents, who appear in no way to be jealous of one ahother. KENNEDY J. P. ORTON.

University College of North Wales, Bangor, April 21 .

The Measurement of Mass.

IN the notice of my little book, "Radium Explained," on April 6, twenty-nine lines are devoted to showing that I have reached a wrong conclusion through not knowing that mass is measured by inertia, and I am corrected in these words:- " how is the quantity of matter to be ascertained? The choice practically lies between defining mass by inertia at a given speed or by gravity. . . A As, however, gravity depends on local circumstances, while inertia (at given velocity) does not, the latter property is preferred for the definition of mass, as being more fundamental.' So far from rejecting this principle, I state it, in almost the same terms, on p. 84 of my book:- "Mass, or quantity of matter, is usually ascertained by weighing. But weight is merely the force with which the earth attracts, and this varies with our position on its surface. To get an absolute test of mass, which would be independent of position, we may measure the force required to move or stop a body at a certain speed." And nowhere in the book have I supported any argument by the repudiation of the principle here clearly stated. This is a question of fact; the other objection taken is equally illfounded, but, being on a controversial point, it cannot be dealt with so briefly.

West Ealing, May ז.

\section{Properties of Rotating Bodies.}

Prof. W. H. Pickering, in Nature of Aprif 27 (p. 608), refers to the property which a rotating body possesses of assimilating, in certain circumstances, its axis of rotation to a secondary axis of rotation or revolution impressed upon it, and he mentions the fact that this property is rarely described.

It was fully discussed in an elementary lecture given by Prof. Perry at the Royal Institution about fifteen years ago, and afterwards published in the Romance of Science Series under the title "Spinning Tops."

\section{E. W. ROWNTREE.}

20 Queen Square, W.C., May I. 